\title{
ARTIGO
}

\section{Trabalho Escravo e Pandemia: os desafios da Inspeção do Trabalho na promoção do trabalho digno}

\author{
Slave Labor and pandemic: \\ the challenges of Labor Inspection in promoting decent work
}

\section{Maurício Krepsky Fagundes}

Auditor-Fiscal do Trabalho, chefe da Divisão de Fiscalização para Erradicação do Trabalho Escravo (DETRAE) e coordenador do Grupo Especial de Fiscalização Móvel (GEFM). Graduado em Física pela Universidade de Brasília.

RESUMO: A pandemia do novo coronavírus afetou não só a economia brasileira mas também o caminho percorrido pela Inspeção do Trabalho na promoção do trabalho decente. Pela ótica da experiência de sucesso no combate ao trabalho análogo ao de escravo, esse artigo apresenta uma possibilidade de atuação eficiente por meio de transparência ativa e controle social, ferramentas que podem ser medidas eficazes de atuação do Brasil em um cenário de restrições nas relações de trabalho.

Palavras-chave: fiscalização, trabalho decente, vulnerabilidade social, coronavírus, Agenda 2030 ONU.

\begin{abstract}
The new coronavirus pandemic affected not only the brazilian economy, but also the path taken by the Labor Inspection in combating slave-like work conditions and in promoting decent work. From the perspective of the successful experience in combating slave-like work, this article presents a possibility of efficient action through active transparency and social control, tools that can be effective measures of Brazil's performance in a scenario of restrictions on labor relations.
\end{abstract}

Keywords: slavery; inspection, decent work, social vulnerability, coronavirus, UN 2030 Agenda. 


\section{INTRODUÇÃO}

No primeiro semestre de 2020, a Inspeção do Trabalho alcançou a marca de 55 mil trabalhadoras e trabalhadores resgatados de condições análogas as de escravo no Brasil. O início da política pública de combate ao trabalho escravo ocorreu com a criação do Grupo Especial de Fiscalização Móvel (GEFM), que atua em todo país e este ano completou 25 anos de existência, coordenado pela Inspeção do Trabalho tendo apoio de parcerias institucionais formadas ao longo do tempo. Participam das operações do GEFM a Polícia Federal (PF), a Polícia Rodoviária Federal (PRF), a Defensoria Pública da União (DPU), o Ministério Público do Trabalho (MPT) e o Ministério Público Federal (MPF).

A criação do GEFM em 1995 foi fato decorrente de o governo brasileiro admitir a existência de trabalho escravo no país perante a comunidade internacional. $\mathrm{Da}$ resposta a uma pressão internacional, a história do combate ao trabalho escravo no Brasil passou a ser referência, reconhecida pela Organização Internacional do Trabalho (OIT) como um modelo de boa prática para outros países.

Contudo, a pandemia instalada pelo novo coronavírus refletiu em preocupações para a execução da política pública. Medidas adicionais de saúde e segurança para realização das operações de combate ao trabalho precisaram ser tomadas, exigindo mais planejamento e articulação. Da mesma forma, o iminente aumento do desemprego pressiona o aumento da vulnerabilidade social, podendo exercer força em sentido contrário à erradicação do trabalho escravo contemporâneo no Brasil.

Diante desse cenário, ações conjuntas em todas as áreas que promovam o trabalho digno necessitam ser potencializadas e as boas práticas compartilhadas, a fim de que a proteção dos trabalhadores não retroceda no que diz respeito à saúde e segurança no trabalho e a direitos humanos.

\section{BOAS PRÁTICAS DA INSPEÇÃO DO TRABALHO}

Desde a criação do GEFM e o início da política pública de combate ao trabalho escravo, foram mais de 55 mil trabalhadores e trabalhadoras resgatadas dessa condição e mais de R $\$ 108$ milhões recebidos pelos trabalhadores a título de verbas salariais e rescisórias durante as operações, conforme dados oficiais disponíveis no Radar do Trabalho Escravo da Subsecretaria de Inspeção do Trabalho (SIT). O valor atualizado ano a ano das verbas rescisórias recebidas por trabalhadores resgatados pelo Índice Nacional de Preços ao Consumidor Amplo (IPCA/IBGE) até junho/2020 é de aproximadamente R $\$ 186$ milhões.

Laborare. Ano III, Número 5, Jul-Dez/2020, pp. 87-105. ISSN 2595-847X. https://revistalaborare.org/ DOI: https://doi.org/10.33637/2595-847x.2020-58 


\section{Maurício Krepsky Fagundes}

O trabalho realizado em condição análoga a de escravo, sob todas as formas, constitui atentado aos direitos humanos fundamentais e à dignidade do trabalhador, sendo dever dos auditores-fiscais do Trabalho combater a sua prática. Segundo a Subprocuradora-Geral da República Raquel Dodge, a divulgação dos resultados dessa política pública e a transparência dos atos da Inspeção do Trabalho atendem a princípios constitucionais:

A Portaria Interministerial 4/2016, assim como as demais impugnadas já revogadas, nada mais é do que instrumento administrativo concebido para dar concretude aos princípios constitucionais da publicidade, da transparência da ação governamental e do acesso à informação.

A Lei n. ${ }^{\circ}$ 12.527, de 18 de novembro de 2011, conhecida como Lei de Acesso à Informação (LAI), regula o acesso a informações, conforme o previsto no inciso XXXIII do art. $5^{\circ}$, no inciso II do $\S 3^{\circ}$ do art. 37 e no $\S 2^{\circ}$ do art. 216 da Constituição Federal:

Art. $5^{\circ}$ Todos são iguais perante a lei, sem distinção de qualquer natureza, garantindo-se aos brasileiros e aos estrangeiros residentes no País a inviolabilidade do direito à vida, à liberdade, à igualdade, à segurança e à propriedade, nos termos seguintes:

XXXIII - todos têm direito a receber dos órgãos públicos informações de seu interesse particular, ou de interesse coletivo ou geral, que serão prestadas no prazo da lei, sob pena de responsabilidade, ressalvadas aquelas cujo sigilo seja imprescindível à segurança da sociedade e do Estado

Art. 216. Constituem patrimônio cultural brasileiro os bens de natureza material e imaterial, tomados individualmente ou em conjunto, portadores de referência à identidade, à ação, à memória dos diferentes grupos formadores da sociedade brasileira, nos quais se incluem:

Laborare. Ano III, Número 5, Jul-Dez/2020, pp. 87-105. ISSN 2595-847X. https://revistalaborare.org/ DOI: https://doi.org/10.33637/2595-847x.2020-58 
$\S 2^{\circ}$ Cabem à administração pública, na forma da lei, a gestão da documentação governamental $\mathrm{e}$ as providências para franquear sua consulta a quantos dela necessitem.

Em seu art. $8^{\circ}$, a LAI prevê a transparência ativa dos órgãos, ou seja, independentemente do requerimento de interessados:

Art. $8^{\circ}$ É dever dos órgãos e entidades públicas promover, independentemente de requerimentos, a divulgação em local de fácil acesso, no âmbito de suas competências, de informações de interesse coletivo ou geral por eles produzidas ou custodiadas.

A Organização das Nações Unidas (ONU) reconheceu em 2016 que a criação do Grupo Especial de Fiscalização Móvel, coordenado pela auditoria-fiscal do trabalho, é uma das iniciativas fundamentais ao enfrentamento do trabalho escravo contemporâneo, assim como a criação do Cadastro de Empregadores que tenham submetido trabalhadores a condição análoga à de escravo.

Em 2019, um estudo da Organização Internacional para Migrações (OIM) e do Foreign Commonwealth Office do Reino Unido para contribuir com o desenvolvimento e o fortalecimento de políticas públicas e programas para enfrentamento da escravidão moderna elogiou o combate ao trabalho escravo no Brasil e definiu o Cadastro de Empregadores como o maior instrumento de identificação de empregadores que submetem trabalhadores a condições análogas às de escravo.

Sobre a vitimização de empregadores incluídos na "lista suja" e a corrida ao Poder Judiciário para ocultar a divulgação de casos de trabalho escravo, a Organização Internacional do Trabalho (OIT) se manifestou em 2007:

"Curiosamente, no entanto, a utilização do epíteto 'Lista Suja' parece projetar também um efeito reverso, qual seja o de vitimizar os empregadores incluídos no referido cadastro de modo a permitir que, no bojo das mais diversas ações judiciais com que tentam ver seus nomes excluídos do cadastro, tentem sensibilizar o Poder Judiciário para a obtenção de decisões favoráveis, em especial as de caráter liminar (...) os empregadores quase sempre se apresentam como indivíduos produtivos e altruístas que empreendem seus negócios com vistas ao crescimento do país, gerando empregos e pagando impostos. Dentro desse contexto, o fato de cometer 'irregularidades trabalhistas' - modo como usualmente se referem às práticas que caracterizam o trabalho escravo - parecelhes algo normal e corriqueiro. Igualmente, julgam absurda a possibilidade de que

Laborare. Ano III, Número 5, Jul-Dez/2020, pp. 87-105. ISSN 2595-847X. https://revistalaborare.org/ DOI: https://doi.org/10.33637/2595-847x.2020-58 
sejam surpreendidos com a inclusão de seus nomes num cadastro que os exponha ao público de forma negativa".

Em outra publicação, a OIT ressalta o papel das empresas, o caráter pedagógico do Cadastro e o efeito multiplicador indireto das ações de inspeção do trabalho:

"No Brasil, o Pacto Nacional pela Erradicação do Trabalho Escravo é um processo paralelo às inspeções trabalhistas, que relaciona compromissos das empresas para acabar com o trabalho forçado em suas próprias operações e cadeias de fornecimento, e desistir de negociar com empresas que fazem uso de trabalho forçado, como detectados e listados publicamente pela autoridade de inspeção do trabalho. Esse processo aprimora a fiscalização do trabalho, espalhando seus efeitos dissuasivos para empresas que não foram diretamente sujeitos a inspeção ou investigação".

O Pacto Nacional pela Erradicação do Trabalho Escravo foi resultado de um estudo aprofundado de cadeias produtivas relativas a nomes incluídos no Cadastro de Empregadores, segundo um estudo da OIT de 2006:

"Essa é a primeira etapa do envolvimento do setor privado para que a responsabilidade social das empresas fale mais alto diante desses crimes contra os direitos humanos. Em parceria com a ONG Repórter Brasil e a Secretaria Especial dos Direitos Humanos, foi identificada a cadeia produtiva da escravidão no Brasil com base nas 'listas sujas' acima mencionadas. Sob o apoio e a supervisão do Instituto Ethos, foi feito um alerta à sociedade para que as empresas socialmente responsáveis cortassem os contratos com fornecedores que estivessem inseridos nessa teia que utiliza mão de obra escrava. O resultado desse trabalho foi o Pacto Nacional pela Erradicação ao Trabalho Escravo, que foi assinado no dia 19 de maio de 2005 em duas solenidades na Procuradoria-Geral da República e no Conselho de Desenvolvimento Econômico e Social, por mais de 80 empresas públicas e privadas".

A Comissão do Setor Financeiro da Iniciativa de Liechtenstein sobre Escravidão Moderna e Tráfico de Pessoas foi criada a partir de uma demanda de um grupo formado pelos colegiados G7, G20, Assembleia Geral das Nações Unidas e Conselho de Segurança das Nações Unidas para que os governos fizessem parceria com o setor privado para abordar escravidão moderna e tráfico de pessoas.

Em seu relatório de setembro de 2019, essa comissão, ao enaltecer em várias partes do mundo instrumentos chave contra a escravidão e contra o tráfico de pessoas, cita a Federal Dirty List (Lista Suja Federal, tradução livre), bem como a consistência e confiabilidade dos dados que ela publica:

Laborare. Ano III, Número 5, Jul-Dez/2020, pp. 87-105. ISSN 2595-847X. https://revistalaborare.org/ DOI: https://doi.org/10.33637/2595-847x.2020-58 
"Desde o início dos anos 2000, o governo brasileiro mantém e publica uma lista de empresas flagradas (por meio de inspeções trabalhistas de campo) utilizando trabalho escravo. A inclusão nessa lista se tornou um indicador-chave pelo qual o setor financeiro brasileiro avaliava o risco social em suas atividades. Relações reais e potenciais, com o governo recomendando formalmente essa abordagem.

Instituições financeiras públicas e privadas, incluindo o Banco do Brasil, o Banco da Amazônia, o Banco do Nordeste e o Banco Nacional de Desenvolvimento Econômico e Social (BNDES), recusaram crédito a empresas incluídas na lista suja - nome coloquial do banco de dados emitido pelo governo dos empregadores responsáveis pelo uso do trabalho escravo - com bancos privados protegidos contra ações legais pelo fato de a lista ter sido emitida pelo governo (tradução livre)".

Mais recentemente, no Trafficking in Persons Report 2020 (Relatório de Tráfico de Pessoas 2020, tradução livre) do governo do Departamento de Estado dos Estados Unidos da América (EUA), em capítulo específico sobre o Brasil, o Cadastro de Empregadores foi citado como uma das ferramentas mais eficazes de enfrentamento ao trabalho escravo:

“As autoridades não fizeram esforços para reduzir a demanda por atos sexuais comerciais. No entanto, as autoridades fizeram esforços para reduzir a demanda por trabalho forçado. A SIT publicou a lista suja, que tornou públicos os nomes de indivíduos e empresas responsabilizadas por utilizar trabalho escravo.

\section{(...)}

Enquanto a lista suja continua sendo uma das ferramentas mais eficazes do Brasil para reduzir a demanda por trabalho escravo, a criminalização inadequada desses delitos dificultou o progresso na luta contra o tráfico para exploração laboral”.

Percebe-se nesse relatório, a importância do Cadastro também na visão do governo dos EUA, colocando-o em posição de destaque histórico no combate ao trabalho escravo.

Recentemente, o Supremo Tribunal Federal (STF) julgou constitucional a criação do Cadastro de Empregadores que tenham submetido trabalhadores à condição análoga à de escravo, a chamada "lista suja do trabalho escravo". A decisão, por maioria de votos, foi proferida na Arguição de Descumprimento de Preceito Fundamental

Laborare. Ano III, Número 5, Jul-Dez/2020, pp. 87-105. ISSN 2595-847X. https://revistalaborare.org/ DOI: https://doi.org/10.33637/2595-847x.2020-58 
(ADPF) 509, ajuizada pela Associação Brasileira de Incorporadoras Imobiliárias (ABRAINC), na sessão virtual encerrada em 14/9/2020.

O único voto contrário ao do ministro Marco Aurélio Mello, relator da ação, foi o do ministro Alexandre de Moraes, pelo não reconhecimento da legitimidade da ABRAINC em propor a ADPF. Esse posicionamento da Suprema Corte significou o reconhecimento da constitucionalidade da Portaria Interministerial MTE/MMIRDH n. $^{\circ} 4$, de 11 de maio de 2016 e consequentemente do Cadastro de Empregadores.

A decisão do STF é de extrema importância e vem confirmar que a publicação do Cadastro de Empregadores significa o exercício de transparência ativa exercido pela Administração, consoante o princípio constitucional da publicidade e, em nível infraconstitucional, com amparo na Lei de Acesso à Informação (Lei n. ${ }^{\circ}$ 12.527/2011), que prevê expressamente o direito de acesso à informação, sendo um dever dos órgãos públicos promoverem, independentemente de requerimentos, a divulgação, em local de fácil acesso, no âmbito de suas competências, de informações de interesse coletivo ou geral.

\section{A VULNERABILIDADE SOCIAL E A PRECARIZAÇÃO DO TRABALHO}

Em um contexto de pandemia, as desigualdades sociais foram amplamente visualizadas no Brasil, desde o acesso a serviços de saúde de qualidade até mesmo a um trabalho digno.

Conforme dados da Pesquisa Nacional por Amostra de Domicílios (PNAD COVID19), divulgados pelo Instituto Brasileiro de Geografia e Estatística (IBGE) de julho/2020, na semana de $19 / 7$ a 25/7, de 89 milhões de pessoas ocupadas, apenas 8,3 milhões estavam em trabalho remoto, sendo que, destes, $31,1 \%$ possuíam ensino superior completo ou pós-graduação, a maior proporção dentre os que estavam em trabalho remoto durante a pandemia.

Esse número de 8 milhões de pessoas (9\% do total de pessoas ocupadas) foi praticamente constante desde $3 / 5 / 2020$, ou seja, as pessoas que poderiam trabalhar remotamente ainda o fazem e pode ser que continuem a fazê-lo mesmo após o término das restrições sociais. Entretanto, grande parte dos trabalhadores não tem essa opção, sendo que além do risco de infecção no ambiente de trabalho e no trajeto de suas casas para o trabalho, também suportam condições de insegurança no trabalho ou até mesmo condições análogas às de escravidão.

Laborare. Ano III, Número 5, Jul-Dez/2020, pp. 87-105. ISSN 2595-847X. https://revistalaborare.org/ DOI: https://doi.org/10.33637/2595-847x.2020-58 
O número de trabalhadores encontrados em condição análoga à de escravo em julho e agosto de 2020 foi o dobro do primeiro semestre do ano, momento em que foi atualizado o Radar do Trabalho Escravo da SIT. Até 30/6/2020, mesmo em plena pandemia, 231 trabalhadores e trabalhadoras foram resgatados de situações de escravidão contemporânea em todo país. Em 27/8/2020, esse número já era de 462 resgatados.

Apenas no mês de agosto, foram 119 trabalhadores resgatados (25\% do total do ano). As fiscalizações trabalhistas que resultaram em resgate de trabalhadores foram registradas na BA, RS, MG, MA, RO, PI e no entorno do DF, onde foram encontrados 28 trabalhadores em condições degradantes de trabalho e vida em uma obra de um condomínio de Águas Lindas/GO.

Por todo o histórico de atuação da Inspeção do Trabalho contra a escravidão contemporânea e pelo valor que a dignidade humana assume nas relações de trabalho, as demais áreas que se dedicam a promover o trabalho digno necessitam ter uma visão de macro conjuntura, principalmente para fazer-se frente aos efeitos da pandemia.

Conforme conceituação da Organização Internacional do Trabalho (OIT), o trabalho digno abrange vários elementos:
a) oportunidades para realizar um trabalho produtivo com uma remuneração justa;
b) segurança no local de trabalho e proteção social para as famílias;
c) melhores perspectivas de desenvolvimento pessoal e integração social; d)
liberdade para expressar as suas preocupações;
e) organização e participação nas decisões que afetam as suas vidas; e
f) igualdade de oportunidades e de tratamento. (grifo nosso)

A OIT também reforça o papel das Normas Internacionais para a garantia do trabalho decente e de respeito aos direitos humanos no contexto de pandemia:

As Normas Internacionais do Trabalho contêm orientações específicas para garantir que haja trabalho decente no contexto da resposta à crise, incluindo orientações que podem ser relevantes para o atual surto de COVID-19. Uma das normas internacionais mais recentes, a Recomendação sobre Emprego e Trabalho Decente para Paz e Resiliência, 2017 ( $\left.\mathrm{N}^{\circ} 205\right)$, que foi adotada por uma esmagadora maioria de todos os constituintes, enfatiza que as respostas a crises precisam garantir o respeito por todos os direitos humanos e pelo Estado de direito, incluindo o respeito pelos princípios e direitos fundamentais no trabalho e pelas Normas Internacionais do Trabalho. (grifo nosso)

Laborare. Ano III, Número 5, Jul-Dez/2020, pp. 87-105. ISSN 2595-847X. https://revistalaborare.org/ DOI: https://doi.org/10.33637/2595-847x.2020-58 


\section{Maurício Krepsky Fagundes}

Conforme a edição semanal da PNAD COVID-19, divulgada em 14/8/2020, a taxa de desocupação atingiu 12,9 milhões de pessoas na quarta semana de julho/2020, sendo que na primeira semana de maio, quando a pesquisa teve início, 9,8 milhões estavam sem trabalho. Logo, pelo menos três milhões de pessoas perderam o trabalho em razão da pandemia até o momento.

Esse contingente sem trabalho, em um momento de recessão, está sujeito a renunciar a direitos conquistados (ANTUNES, 2020):

"O resultado está em toda parte: precarização ampliada e multiforme, onde os trabalhadores e trabalhadoras são as vítimas principais. Em épocas de expansão, ampliam-se os empregos, como no setor de serviços, dotados de alta rotatividade, pouca qualificação e baixa remuneração, de que são exemplos os trabalhos nas plataformas digitais e nos aplicativos, no telemarketing e call center, hipermercados, hotéis e restaurantes, comércio etc.

Em fases de crise e de recessão, como as que estamos vivenciando não só nos países do Norte, mas também no Sul do mundo, a resultante é ainda mais conhecida: erosão devastadora dos empregos e corrosão e demolição exponencial dos direitos do trabalho".

Essa renúncia de direitos em nome da sobrevivência pode jogar trabalhadores para a informalidade, exigir de toda família uma parcela de participação para economia doméstica (o que envolveria o trabalho infantil), e até mesmo a submissão a riscos de acidentes ou adoecimentos do trabalho. Nesse cenário, a redução a uma condição análoga à escravidão seria mais um patamar inferior no desmantelo de uma esperança de trabalho digno.

Os casos de trabalho escravo registrados este ano durante a pandemia não são dela decorrentes, eles possuem raízes na desigualdade social e na vulnerabilidade socioeconômica de milhares de indivíduos que são obrigados a crer que qualquer trabalho é melhor que nenhum trabalho (CARDOSO et al., 2020). O trabalho escravo não está respeitando quarentena ou isolamento social, continua infectando nossa sociedade. Da mesma forma, a prevenção de acidentes e adoecimentos do trabalho, que já era um grande desafio para a Inspeção do Trabalho, torna-se ainda maior com o risco biológico que permeia toda sociedade.

Os desafios da fiscalização do trabalho começam internamente, com um efetivo reduzido de auditores-fiscais do trabalho. Conforme Nota Pública de 30 de junho de 2020, emitida pela Comissão Nacional de Erradicação do Trabalho Escravo (CONATRAE), o colegiado clama que a União adote providências para realização de

Laborare. Ano III, Número 5, Jul-Dez/2020, pp. 87-105. ISSN 2595-847X. https://revistalaborare.org/ DOI: https://doi.org/10.33637/2595-847x.2020-58 
concurso público e preenchimento dos 1.553 cargos vagos na carreira da auditoriafiscal do trabalho.

Tanto no combate ao trabalho escravo quanto na prevenção de acidentes e doenças do trabalho, a Inspeção do Trabalho é a linha de frente no contato com graves violações trabalhistas, e em alguns casos a única representação efetiva do Estado nos locais de trabalho, ou seja, na realidade e no cotidiano dos trabalhadores brasileiros.

\section{PRINCÍPIO DA TRANSPARÊNCIA PARA ATOS DE EMBARGO E INTERDIÇÃO E A EXPERIÊNCIA DO REINO UNIDO}

Conforme dados da Subsecretaria de Inspeção do Trabalho (SIT), o número de embargos e interdições por risco grave e iminente de acidentes ou doenças relacionadas ao trabalho, realizados por auditores-fiscais do trabalho, tem diminuído ano a ano desde 2015. Em 2015 foram 6.450 atos com essas finalidades; $5.037 \mathrm{em}$ 2016; 4.821 em 2017; 4.650 em 2018 e 4.436 em 2019.

A legislação brasileira de saúde e segurança e saúde no trabalho é razoável como instrumento na busca do trabalho decente e sadio, inclusive no que tange à salvaguarda da integridade dos trabalhadores por meio do procedimento de embargo e interdição, quando caracterizado o risco grave e iminente à integridade física (SCIENZA; RODRIGUES; 2018). Cabe ressaltar que a Norma Regulamentadora $n .^{\circ}$ 3 (NR-3) foi alterada em 2019, por meio da Portaria n. ${ }^{\circ}$ 1.068/2019 da Secretaria Especial de Previdência e Trabalho (SEPRT).

A Inspeção do Trabalho no Reino Unido publica regularmente os atos administrativos similares aos de embargo e interdição praticados no Brasil, onde a NR-3 define as diretrizes para caracterização de grave e iminente risco de acidente ou doença com grave lesão ao trabalhador, bem como dispõe sobre os instrumentos de embargo e interdição que devem ser adotados pelos auditores-fiscais do trabalho.

Conforme Scienza e Rodrigues (2018), dois tipos de atos administrativos com força executória são praticados como medidas de emergência no Reino Unido, os avisos de proibição e os avisos de melhoria:

"O estudo comparado das disposições legais relacionadas aos procedimentos de igual natureza do embargo e interdição brasileiros revela seu precípuo caráter cautelar, diante da gravidade do risco à integridade dos trabalhadores. Há uma base conceitual homogênea: são medidas de urgência, vinculadas ao poder dever do Estado em fazer cessar a exposição ao risco. Já suas rotinas de aplicação são estabelecidas sob formas diversas, conforme os costumes e práticas nacionais. No

Laborare. Ano III, Número 5, Jul-Dez/2020, pp. 87-105. ISSN 2595-847X. https://revistalaborare.org/ DOI: https://doi.org/10.33637/2595-847x.2020-58 
Reino Unido, o serviço estatal de inspeção do trabalho em segurança e saúde - o Health and Safety Executive (HSE) - é o responsável pela sua execução. As seções 22 e 23 do Health and Safety at Work etc Act (HSWA) permitem que os inspetores do HSE emitam um Aviso de Proibição (Prohibition Notice), determinando a paralisação imediata da atividade que esteja induzindo ou que possa vir, futuramente, a induzir riscos de lesões graves. $\mathrm{O}$ aviso pode ser emitido em nome de qualquer pessoa no controle de um processo ou planta, sem prejuízo de outras disposições. Se o inspetor tiver motivos razoáveis para acreditar que exista risco de graves lesões, sequer é necessária a expressa violação de uma disposição legal para a sua validade. $O$ aviso não pode ser suspenso por um recurso administrativo, mas o requerente poderá apelar para um tribunal do trabalho, buscando a eventual suspensão do efeito, até o seu efetivo julgamento. Os avisos de proibição são publicados e mantidos em um registro on line de acesso universal, durante um período de cinco anos. Infrações menores que exijam correção, porém sem paralisação da atividade, são denominadas improvement notice".

A publicação do HSE difere do Cadastro de Empregadores que tenham submetido trabalhadores a condições análogas às de escravo, principalmente pelo volume de dados e tipo de acesso, pois em pesquisa realizada em 19/8/2020, ele reunia 40.023 registros e possui ferramentas de busca por tipo de aviso e por região, dentre outras.

De forma similar, como o Cadastro de Empregadores no Brasil é conhecido como "lista suja", o Cadastro do HSE é chamado de name and shame website (página de expor e constranger, tradução livre). Conforme Relatório de Pesquisa 339 do HSE, intitulado Promoting health and safety as a key goal of the Corporate Social Responsibility Agenda (Promover a saúde e a segurança como objetivo principal da Agenda de Responsabilidade Social Corporativa, tradução livre), a Comissão Executiva de Saúde e Segurança do HSE (HSC/E) não possui a necessidade de expor e ou constranger, mas deve continuar a informar e a educar, sendo que qualquer suposição de que uma empresa possa estar em desvantagem no mercado como resultado de seu desempenho em saúde e segurança ocupacional servirá para torná-la um problema material.

Associado a isso, o relatório informa que, de acordo com pesquisa de compra ética, a Fundação Nova Economia descobriu que 52\% dos consumidores tinham alguma vez boicotado um produto ou serviço por razões éticas. Dessa forma, não adotar uma gestão adequada de saúde de segurança no trabalho se tornaria um problema real, com prejuízos financeiros à empresa infratora que fosse flagrada submetendo seus trabalhadores a risco de acidente ou adoecimento no trabalho.

Laborare. Ano III, Número 5, Jul-Dez/2020, pp. 87-105. ISSN 2595-847X. https://revistalaborare.org/ DOI: https://doi.org/10.33637/2595-847x.2020-58 
Caso existisse um Cadastro dessa natureza no Brasil, um total 25.394 empresas e pessoas físicas poderiam nele figurar, com base no número de embargos e interdições da Inspeção do Trabalho realizados nos últimos cinco anos. Caso essa informação fosse pública, como o HSE britânico, uma avaliação do risco de negócios empresariais poderia ser mais aprofundada sob esse aspecto, não apenas de saúde e segurança, mas da vida de pessoas.

Caso a preocupação com a integridade física e mental dos trabalhadores não seja suficiente para a adoção de medidas de saúde e segurança ocupacional, a preocupação com a saúde financeira da empresa cumpriria indiretamente o papel de promover o trabalho decente.

A própria Comissão Executiva de Saúde e Segurança do HSE (HSC/E) reconhece no Relatório de Pesquisa 339 que dentre as atividades mais problemáticas do HSE quanto à objetividade de suas funções regulatórias é a política "name and shame" e homologar práticas de empresas. Entretanto, consideram que a Responsabilidade Social Empresarial (RSE) possui um poder maior em elevar o perfil da saúde e segurança ocupacional nas empresas, provendo uma pressão "de cima para baixo" sobre aspectos ambientais e sociais, enquanto o HSE pode promover uma abordagem "de baixo para cima" entre as partes interessadas.

O resultado tende a seguir uma linha de diminuição do problema, como mostram Scienza e Rodrigues (2018), em comparação à prática brasileira:

"As decorrentes estatísticas do HSE britânico na aplicação de tais medidas, quando comparadas com as de sua contraparte brasileira, revelam a banalização radical da morte pelo trabalho em nosso país. Este serviço, no biênio de 2014/2015, realizou 4.117 determinações para paralisação imediata de atividades (prohibition notice) em face de riscos à integridade física de trabalhadores (o equivalente ao nosso embargo e interdição) e 8.288 notificações para adoção de medidas corretivas (improvement notice), sem efeito de paralisação. Portanto, uma determinação de paralisação para cada duas notificações sem efeito de paralisação, aproximadamente oito vezes superior à média da inspeção do trabalho brasileira no mesmo período. Já o estudo comparado de suas taxas de óbito (mesmo se ressalvando as diferenças no conceito e abrangência da taxa) revela que o Reino Unido possui 0,46 óbitos para cada grupo de $100 \mathrm{mil}$ trabalhadores, ao passo que o Brasil possui taxa oficial de seis óbitos a cada 100 mil trabalhadores. Assim, é cerca de doze vezes mais provável a morte de um trabalhador brasileiro em acidente de trabalho do que a de um trabalhador britânico - o que permite inferir uma maior quantidade e severidade de situações de risco (inclusive as passíveis de paralisação imediata) muito superior no Brasil”.

Laborare. Ano III, Número 5, Jul-Dez/2020, pp. 87-105. ISSN 2595-847X. https://revistalaborare.org/ DOI: https://doi.org/10.33637/2595-847×.2020-58 
Percebe-se que a Inspeção Britânica de saúde e segurança no trabalho (HSE) buscou soluções além da própria regulação e fiscalização, em uma agenda de responsabilidade social empresarial, onde a promoção do trabalho decente é um problema de toda a sociedade.

Da mesma forma, o trabalho escravo contemporâneo não é um problema apenas da Inspeção do Trabalho, no âmbito da apuração administrativa, ou apenas da Polícia Federal ou do Ministério Público Federal, no âmbito da investigação penal, mas sim de toda a sociedade, pois os efeitos deletérios dessa prática mancham o tecido social.

\section{TRANSPARÊNCIA DOS ATOS DA INSPEÇÃO E CONTROLE SOCIAL}

Segundo Mércia Silva, diretora executiva do Instituto Pacto Nacional pela Erradicação do Trabalho Escravo (InPACTO), a promoção do trabalho digno está intimamente relacionada à reponsabilidade empresarial:

\footnotetext{
“A construção de um Brasil livre do trabalho escravo passa pela consolidação da responsabilidade das grandes empresas com as médias e pequenas, nos diversos elos de sua cadeia produtiva, tanto em termos de qualidade e gestão do negócio, quanto na defesa e promoção da dignidade e dos direitos humanos".
}

O InPACTO é uma organização sem fins lucrativos que mobiliza os diferentes setores na promoção do trabalho digno há 15 anos, desde a criação do Pacto Nacional pela Erradicação do Trabalho Escravo. A exigência de maior transparência sobre as relações entre os diversos elos das cadeias produtivas se tornou uma obrigação para empresas que buscam essa sustentabilidade socioambiental (SILVA, 2018).

A Organização para a Cooperação e Desenvolvimento Econômico (OCDE) possui um guia de devida diligência para empresas multinacionais evitarem impactos negativos que podem se associar às suas cadeias de valor. A aproximação do Brasil com a OCDE e a sua aceitação como país membro dependem da aplicação interna dos padrões de devida diligência, que está relacionado às normas de conduta empresarial responsável.

Segundo as diretrizes da OCDE, as empresas multinacionais devem observar as normas internacionais e, antes de tudo, as legislações nacionais onde estão domiciliadas. Nos países em que as normas internas entram em conflito com normas internacionais, a devida diligência pode ajudar as empresas a se manter no padrão OCDE. O manual ainda alerta que a legislação nacional também pode exigir que as empresas tomem atitudes concretas previstas na conduta empresarial, como leis

Laborare. Ano III, Número 5, Jul-Dez/2020, pp. 87-105. ISSN 2595-847X. https://revistalaborare.org/ DOI: https://doi.org/10.33637/2595-847x.2020-58 
relacionadas a corrupção, a formas modernas de escravidão ou a minerais procedentes de áreas afetadas por conflitos e de alto risco.

Em relação à informação, a conduta empresarial responsável envolve a informação aos trabalhadores sobre exposição a substâncias perigosas, divulgação de resultados ou implicações ambientais para uma proteção efetiva dos direitos a vida e à saúde.

Apesar de a responsabilidade social empresarial exigir a promoção da devida diligência, o que demanda iniciativa para monitoramento de cadeia de valor, o Estado deve cumprir o seu papel de transparência ativa, de forma a auxiliar as empresas na identificação de possíveis riscos.

Ao passo que a Constituição Federal prevê o acesso à informação como direito fundamental, a Lei n. ${ }^{\circ}$ 12.527/2011, conhecida como Lei de Acesso à Informação (LAI), determina a transparência ativa dos órgãos, ou seja, independentemente de requerimento dos interessados:

Art. $8^{\circ}$ É dever dos órgãos e entidades públicas promover, independentemente de requerimentos, a divulgação em local de fácil acesso, no âmbito de suas competências, de informações de interesse coletivo ou geral por eles produzidas ou custodiadas.

O Cadastro de empregadores que tenham submetido trabalhadores a condição análoga à de escravo, mais conhecido como "lista suja", é regulamentado com base nesses princípios, os quais poderiam nortear a divulgação de outras informações de interesse coletivo, incluídas as que envolvem responsabilidade social empresarial, tais como saúde e segurança no trabalho, trabalho infantil, discriminação, assédio moral, sonegação fiscal, informalidade e embaraço à fiscalização.

A exemplo da publicação de atos de embargos e interdição do HSE do Reino Unido, além de outros instrumentos semelhantes publicados pelas inspeções do trabalho de todo mundo, dentre elas, as da Argentina, da Nova Zelândia e da Austrália, os órgãos de fiscalização precisam desempenhar esse papel de transparência, a fim de envolver o setor produtivo na erradicação de problemas crônicos.

Para isso, é fundamental que embargos, interdições e autuações da Inspeção do Trabalho, que relatam detalhadamente casos que atentem não só contra a dignidade, mas também contra a própria vida e a saúde dos trabalhadores, sejam publicados regularmente, independentemente de solicitações. Assim, a publicidade

Laborare. Ano III, Número 5, Jul-Dez/2020, pp. 87-105. ISSN 2595-847X. https://revistalaborare.org/ DOI: https://doi.org/10.33637/2595-847×.2020-58 


\section{Maurício Krepsky Fagundes}

governamental fará com que os núcleos de responsabilidade social das empresas despertem para possíveis riscos, além de potencializar o controle social.

A sociedade necessita saber quais empresas negligenciam medidas de saúde e segurança no trabalho e preferem lucrar à custa das vidas as quais empregam. Isso é ainda mais premente em um cenário de pandemia, onde qualquer estabelecimento possui elevado risco à vida dos empregados, de suas famílias e da sociedade.

\section{CONCLUSÃO}

Desde 2003, o Cadastro de Empregadores que tenham submetido trabalhadores a condições análogas às de escravo assumiu um papel histórico de importância e referência como modelo de atuação eficaz do governo brasileiro ao não permitir, primeiramente, que o próprio governo financiasse indiretamente negócios que exploravam trabalhadores em condição de escravidão contemporânea. Em um segundo momento, tornou-se uma poderosa ferramenta de controle social.

Pela confiabilidade dessa informação, oriunda das fiscalizações no âmbito administrativo-trabalhistas realizadas pela auditoria-fiscal do trabalho, o Cadastro de Empregadores alcançou outras dimensões, chegando até mesmo a uma esfera de name and shame policy (política de expor e constranger, tradução livre), semelhante aos instrumentos da Inspeção do Trabalho no Reino Unido ou da Austrália.

As ações do GEFM e dos projetos regionais de combate ao trabalho escravo, que ocorrem no âmbito das unidades regionais da Inspeção do Trabalho, quando não constatam condições que ensejam o resgate de trabalhadores, não raro também encontram trabalho infantil, incluindo suas piores formas; situações de grave e iminente risco de acidentes e doenças do trabalho; embaraço à fiscalização e, principalmente, informalidade. Em alguns casos, todas essas irregularidades são encontradas em conjunto, mas apenas a situação de trabalho escravo contemporâneo alcança as janelas da transparência ativa.

Dentre os Objetivos de Desenvolvimento Sustentável (ODS) da Agenda 2030 da ONU, existe o Objetivo 8, que é promover o crescimento econômico sustentado, inclusivo e sustentável, emprego pleno e produtivo e trabalho decente para todas e todos.

Conforme a meta 8.7, o Brasil necessita tomar medidas imediatas e eficazes para erradicar o trabalho forçado, acabar com a escravidão moderna e o tráfico de pessoas até 2030. A meta 8.8 dos ODS avança para a proteção da saúde e segurança dos

Laborare. Ano III, Número 5, Jul-Dez/2020, pp. 87-105. ISSN 2595-847X. https://revistalaborare.org/ DOI: https://doi.org/10.33637/2595-847x.2020-58 
trabalhadores, ao exigir a proteção dos direitos trabalhistas e promover ambientes de trabalho seguros e protegidos para todos os trabalhadores.

Se, atualmente, erradicar a escravidão moderna no país em 10 anos e acabar com todas as formas de trabalho infantil em cinco anos soa como uma meta ousada, ou até inatingível, no que diz respeito ao combate ao trabalho escravo, poderia parecer um horizonte totalmente inalcançável caso instrumentos como o Cadastro de Empregadores, em conjunto com outras iniciativas governamentais e da sociedade civil, não fossem criadas.

Empresas que, por falta de uma gestão adequada de saúde e segurança no trabalho, escolhem expor seus empregados a riscos graves de acidente e adoecimento, privilegiando uma economia de despesa mortal para a classe trabalhadora, igualmente poderiam ser relacionadas pela Inspeção do Trabalho e medidas mais amplas poderiam ser tomadas para enfrentamento desse descaso com a vida humana.

Desprezando-se estudo comparado de normas ou de eficiência entre os efeitos dos atos de aviso de proibição e aviso de melhoria do Reino Unido e os atos de embargo e interdição do Brasil, percebe-se que a transparência dos flagrantes de situação de grave e iminente risco no ambiente de trabalho poderia proporcionar um olhar mais amplo da Inspeção do Trabalho sob o aspecto da saúde e segurança ocupacional, bem com um maior engajamento das partes interessadas.

No que diz respeito à saúde e à segurança no trabalho em tempo de pandemia, os riscos da atividade não mais se restringem ao chão de fábrica, mas podem se disseminar na sociedade com a facilidade de propagação do coronavírus. Ao menosprezar regras mínimas de saúde e segurança no trabalho, empregadores podem colocar em risco um número indeterminado de pessoas, agravar a crise do sistema de saúde, fazendo com que municípios adotem medidas de restrição mais rígidas e, consequentemente, prejudiquem a economia.

A pandemia reforçou a necessidade da existência de um Estado que atenda aos anseios da população, assim como de uma sociedade que se perceba como um todo, onde empregadores não podem explorar a saúde, a segurança e a dignidade dos trabalhadores, sobretudo em um cenário pandêmico, no qual a vida laboral se conecta cada vez mais com a vida pessoal e familiar.

\section{REFERÊNCIAS}

Laborare. Ano III, Número 5, Jul-Dez/2020, pp. 87-105. ISSN 2595-847X. https://revistalaborare.org/ DOI: https://doi.org/10.33637/2595-847x.2020-58 
BANCO CENTRAL DO BRASIL. Calculadora do Cidadão. Disponível em: https://www3.bcb.gov.br/CALCIDADAO/publico/exibirFormCorrecaoValores.do? method=exibirFormCorrecaoValores\&aba=1. Acesso em: 21 ago. 2020.

BRASIL. CONSTITUIÇÃO FEDERAL DE 1988. Disponível em: http://www.planalto.gov.br/ccivil_03/constituicao/constituicaocompilado.htm. Acesso em: 21 ago. 2020.

Disponível NORMA REGULAMENTADORA No 03 - EMBARGO E INTERDIÇÃO. https://enit.trabalho.gov.br/portal/images/Arquivos_SST/SST_NR/NR-03-atualizada2019.pdf. Acesso em: 21 ago. 2020.

CARDOSO, Lys; FAGUNDES, Maurício; SUZUKI, Natália; BENEDITO, Beatriz; PEREIRA, Guilherme; MOYA, Jobana. O trabalho escravo contemporâneo não teve quarentena. Disponível em: https://politica.estadao.com.br/blogs/gestaopolitica-e-sociedade/o-trabalho-escravo-contemporaneo-nao-teve-quarentena/.

Acesso em: 20 ago. 2020.

COMISSÃO NACIONAL DE ERRADICAÇÃO DO TRABALHO ESCRAVO. Nota Pública. Disponível em: https://mpt.mp.br/pgt/noticias/nota-publica-concursoauditor-fiscal-do-trabalho.pdf. Acesso em: 19 ago. 2020.

HEALTh AND SAFeTY EXECUTIVE. Enforcement Notices Public. Disponível em: https://resources.hse.gov.uk/notices/default.asp . Acesso em: 19 ago. 2020.

\section{RESEARCH REPORT 339. Disponível em:}

https://www.hse.gov.uk/research/rrpdf/rr339.pdf . Acesso em: 19 ago. 2020.

INSTITUTO BRASILEIRO DE GEOGRAFIA E ESTATÍSTICA. Pesquisa Nacional por Amostra de Domicílios - PNAD COVID19. Disponível em: https://www.ibge.gov.br/estatisticas/investigacoes-experimentais/estatisticasexperimentais/27946-divulgacao-semanal-pnadcovid1.html? $=\& \mathrm{t}=$ resultados. Acesso em: 19 ago. 2020.

O IBGE apoiando o combate à COVID19. Disponível em:

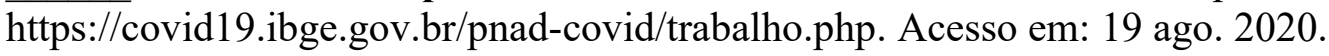

MINISTÉRIO PÚBLICO FEDERAL. Disponível em: http://www.mpf.mp.br/pgr/noticias-pgr/mpf-lista-suja-do-trabalho-escravo-elegitima-e-se-baseia-no-principio-da-transparencia. Acesso em: 19 ago. 2020.

ORGANIZAÇÃO PARA A COOPERAÇÃO E O DESENVOLVIMENTO ECONÔMICO. OCDE Due Diligence Guidance for Responsible Business Conduct, 2018. Disponível em: https://mneguidelines.oecd.org/OECD-Due-Diligence-Guidancefor-Responsible-Business-Conduct.pdf. Acesso em: 19 ago. 2020.

Laborare. Ano III, Número 5, Jul-Dez/2020, pp. 87-105. ISSN 2595-847X. https://revistalaborare.org/ DOI: https://doi.org/10.33637/2595-847x.2020-58 
ORGANIZAÇÃO INTERNACIONAL DO TRABALHO (OIT). As normas da OIT e a COVID-19 (coronavírus). Disponível em: https://www.ilo.org/wcmsp5/groups/public/---americas/---ro-lima/---ilo-brasilia/ documents/publication/wcms_745248.pdf. Acesso em: 21 ago. 2020.

Possibilidades Jurídicas de Combate à Escravidão Contemporânea. Brasília, 2007. Disponível em: https:/www.ilo.org/wcmsp5/groups/public/--americas/---ro-lima/---ilo-brasilia/documents/publication/wcms_227539.pdf . Acesso em: 30 jun. 2020.

Trabalho Digno. Disponível em: https://www.ilo.org/lisbon/temas/WCMS_650867/lang--pt/index.htm . Acesso em: 19 ago. 2020 .

. Labour inspection and private compliance initiatives: Trends and issues. Genebra, p. 28, 2013. Disponível em: https:/www.ilo.org/wcmsp5/groups/public/--ed_dialogue/---lab_admin/documents/meetingdocument/wcms_230798.pdf . Acesso em: 30 jun. 2020.

ORGANIZAÇÃO DAS NAÇÕES UNIDAS (ONU). Trabalho Escravo no Brasil do Século XXI. Brasília, p. 14, 2006. Disponível em: https://www.ilo.org/wcmsp5/groups/public/---americas/---ro-lima/---ilo-brasilia/ documents/publication/wcms_227551.pdf . Acesso em: 30 jun. 2020.

ORGANIZAÇÃO INTERNACIONAL PARA AS MIGRAÇÕES (OIM). Dinámica de la Esclavitud Moderna en Brasil, Colombia, El Salvador, Guatemala, Haití, Honduras, República Dominicana y Venezuela, desde la perspectiva del Reino Unido: Un Análisis Regional. Bogotá, p. 36. 2019.

SCIENZA, Luiz Alfredo; RODRIGUES, Otávio Kolowski. Grave e Iminente Risco à Integridade dos Trabalhadores: superando a morte e a desinformação. In: FILGUEIRAS, Vitor Araújo. Saúde e Segurança do Trabalho no Brasil. Brasília, 2017.

SILVA, Mércia. A responsabilidade das empresas na erradicação do trabalho escravo. Disponível em: https://inpacto.org.br/artigo-a-responsabilidade-dasempresas-na-erradicacao-do-trabalho-escravo/. Acesso em: 20 ago. 2020.

SUBSECRETARIA DE INSPEÇÃO DO TRABALHO (SIT). Painel de Informações e Estatísticas da Inspeção do Trabalho no Brasil - Radar do Trabalho Escravo. Disponível em: https://sit.trabalho.gov.br/radar Acesso em: 27 ago. 2020 .

SUPREMO TRIBUNAL FEDERAL. Lista suja do trabalho escravo é constitucional. Disponível em: http://www.stf.jus.br/portal/cms/verNoticiaDetalhe.asp? idConteudo=451765. Acesso em: 14 set. 2020.

Laborare. Ano III, Número 5, Jul-Dez/2020, pp. 87-105. ISSN 2595-847X. https://revistalaborare.org/ DOI: https://doi.org/10.33637/2595-847x.2020-58 
Maurício Krepsky Fagundes

UNITED STATES OF AMERICA, Department of State. Trafficking In Persons Report June 2020 Disponível em: https://www.state.gov/wp-content/uploads/2020/06/2020-TIP-Report-Complete062420-FINAL.pdf Acesso em: 1 jul. 2020.

Recebido: $23 / 09 / 2020$

Revisado: $18 / 09 / 2020$

Aprovado: 18/09/2020

Laborare. Ano III, Número 5, Jul-Dez/2020, pp. 87-105. ISSN 2595-847X. https://revistalaborare.org/ DOI: https://doi.org/10.33637/2595-847x.2020-58 